\title{
Microstructure Evolution and Mechanical Property Response of 3D-Printed Scalmalloy with Different Heat-Treatment Times at $325{ }^{\circ} \mathrm{C}$
}

\author{
C. N. Kuo ${ }^{1,2, *}$ (1) P. C. Peng ${ }^{2,3}$, D. H. Liu ${ }^{1}$ and C. Y. Chao ${ }^{4}$ \\ 1 Department of Bioinformatics and Medical Engineering, Asia University, Taichung 40250, Taiwan; \\ hani2926@icloud.com \\ 2 3D Printing Medical Research Institute, Asia University, Taichung 40250, Taiwan; william87041@gmail.com \\ 3 Graduate Institute of Biomedical Sciences, China Medical University, Taichung 40250, Taiwan \\ 4 Department of Mechanical Engineering, National Pingtung University of Science and Technology, \\ Pingtung 92043, Taiwan; cychao@mail.npust.edu.tw \\ * Correspondence: cnkuo@asia.edu.tw
}

check for updates

Citation: Kuo, C.N.; Peng, P.C.; Liu, D.H.; Chao, C.Y. Microstructure Evolution and Mechanical Property Response of 3D-Printed Scalmalloy with Different Heat-Treatment Times at $325^{\circ} \mathrm{C}$. Metals 2021, 11, 555.

https://doi.org/10.3390/met11040555

Academic Editor: Andrey Belyakov

Received: 4 March 2021

Accepted: 22 March 2021

Published: 29 March 2021

Publisher's Note: MDPI stays neutral with regard to jurisdictional claims in published maps and institutional affiliations.

\begin{abstract}
According to the material nature, aluminum alloys are widely applied in aerospace, construction, and automotive applications due to their characteristics of being lightweight, having good formability, and having good corrosion resistance. To further improve the degree of the lightweight quality, introducing a new material with high specific strength and a structure with a lightweight design would be efficient. Scalmalloy (Al-4.49Mg-0.71Sc-0.51Mn-0.27Zr-0.07Fe-0.03Si alloy), which exhibits high specific strength and is made by a 3D printing process with less design limitation, has huge application potential. In this study, the selective laser melting (SLM) process was introduced for sample preparation. Through XRD, EBSD, and TEM, the microstructure of the heat-treated samples at $325{ }^{\circ} \mathrm{C}$ with different heat-treatment times was analyzed to evaluate the optimized heat-treatment parameter for 3D printed Scalmalloy. The relationship between the mechanical properties and the variation of precipitation size and volume fraction is discussed in detail in this study.
\end{abstract}

Keywords: scalmalloy; heat treatment; selective laser melting (SLM)

\section{Introduction}

The weight of the products plays an important role in the performance of products in many industries like space, aerospace, and automotive. There are several approaches to achieve weight reduction, such as replacing materials with high specific strength materials, optimizing the structural design, and introducing topology/porous structures through the elimination of excessive design factors. Therefore, the weight reduction potential depends on the ability to manufacture products with high structural complexity and high specific strength materials. However, it is difficult and thus expensive to manufacture products with complex topology/porous structure design through the conventional lightweight materials manufacturing technologies (such as laser welding, hydroforming, or tailored blanks). Additive manufacturing (AM) technology can fulfill both requirements; moreover, the technological benefits of AM come into effect especially during the production of parts with a complexity exceeding the possibilities of conventional manufacturing technologies [1]. Various lightweight designs that introduce porous structures could be fabricated by 3D printing technology and widely used in high-end engineering products such as vehicle parts, aerospace parts, and medical implants [2-10]. Moreover, thanks to the development of the 3D printing process, especially powder bed fusion (PBF) technology, metal materials that are difficult to manufacture by traditional processes are re-emerging and playing a pivotal role in lightweight applications [11-19]. 
One of the advanced lightweight materials that received attention from global researchers is Scalmalloy. With at least $0.6 \mathrm{wt}$.\% addition of Sc, Al-Sc precipitations will be nucleated at high temperatures and provide more nucleation sites which overcome the hot cracking issue of other $\mathrm{Al}$ alloys in the $3 \mathrm{D}$ printing process. Thus, the well-distributed precipitations limit the formation of columnar grain and prevent hot tearing during solidification $[20,21]$. Moreover, compared with the conventional manufacturing technologies, the grain size is smaller, the metallurgy bonding is better, and the precipitate distribution is more uniform, which corresponds to $3 \mathrm{D}$ printing process characteristics such as localized melting and high cooling rate. For example, compared with the samples fabricated by the casting process, the Al- $0.5 \%$ Sc alloy fabricated by SLM exhibits a finer grain size and better mechanical properties, and with the average grain size decreased from 25 to $7 \mu \mathrm{m}$, the yield stress has been increased from 131 to $323 \mathrm{MPa}$, and the elongation has been increased from 3.7 to $10.5 \%$, respectively [22]. Moreover, the grain size and microstructure feature could be altered by changing the 3D printing parameter and thus the mechanical properties of the 3D-printed materials could be affected [20,23-27]. In our previous study, we showed that the grain size can be reduced and the columnar grain can be limited by adjusting parameters and thus significantly improve the yield stress and elongation of the 3D-printed Scalmalloy [19].

However, the yield stress of as-built Scalmalloy is only about $290 \mathrm{MPa}$. Nevertheless, the mechanical properties of Scalmalloy can be further improved through precipitation strengthening by changing the precipitate spacing, size, and volume fraction, which can be affected by the heat-treatment parameters $[1,20,28-30]$. Hence, it is important to study the heat-treatment parameter effects on the mechanical properties based on the microstructure evolution. Referring to previous studies; $325{ }^{\circ} \mathrm{C}$ has been reported as a proper heattreatment temperature for Al-Mg-Sc-Mn-Zr alloys of different Sc contents $[1,20,28]$. To evaluate the heat-treatment time effects at $325^{\circ} \mathrm{C}$ on the mechanical properties based on the microstructure evolution, three different heat treatment times have been conducted on 3Dprinted Scalmalloy samples using selective laser melting (SLM) technology (4, 24, and $48 \mathrm{~h}$ ). The microstructures of the samples with/without heat treatment have been examined to investigate the precipitation and grain size variation by heat treatment. Meanwhile, all the samples were tested using tensile test to explore the relationship between heat-treatment, microstructure, and mechanical properties.

\section{Experimental Procedure}

In this study, all the spherical pre-alloyed Scalmalloy powder was provided by Heraeus Group (Hanau, Germany) and Circle Metal Powder Co., Ltd (Tainan city, Taiwan). The powder size ranged mainly from 20 to $63 \mu \mathrm{m}$ (an SEM image of the pre-alloyed Scalmalloy powders is shown in Figure 1), and the chemical composition, which was measured by Circle Metal Powder Co., Ltd (Tainan city, Taiwan). (determined by Agilent 5110 series ICP-OES followed ASTM E3061-17 standard at $25^{\circ} \mathrm{C}$ ), is about $93.9 \mathrm{wt} \% \mathrm{Al}, 4.49$ wt. $\%$ $\mathrm{Mg}, 0.71$ wt. \% Sc, 0.51 wt. \% Mn, 0.27 wt. \% Zr, 0.07 wt. \% Fe, 0.03 wt. \% Si, and 0.02 wt. \% other elements.

The 3D-printed SLM Scalmalloy was fabricated using a Renishaw AM400 system (Renishaw Inc., Wotton-under-Edge, UK) under an Ar atmosphere. The maximum power of the laser was about $400 \mathrm{~W}$, the scanning rate reached about $2 \mathrm{~m} / \mathrm{s}$, the laser spot size was about $70 \mu \mathrm{m}$, and the thickness of each powder layer was about $30 \mu \mathrm{m}$. For Scalmalloy, the building rate was about $5-20 \mathrm{~cm}^{3} / \mathrm{h}$ and the maximum manufacturing size was about 25 $\times 25 \times 30 \mathrm{~cm}^{3}$. All batches of Scalmalloy samples were fabricated by using the Renishaw AM400 system according to the parameters developed in our previous study; the detailed parameters are shown in Table 1 [19]. To evaluate the heat-treatment time effects on the mechanical properties based on the microstructure evolution, the heat treatment of the Scalmalloy samples in this work was conducted at $325^{\circ} \mathrm{C}$ for $0,4,24$, and $48 \mathrm{~h}$. The samples used for tensile testing and microstructure examination were obtained from more than 
3 batches. Additionally, at least 3 tests were performed to ensure the reproducibility of results.

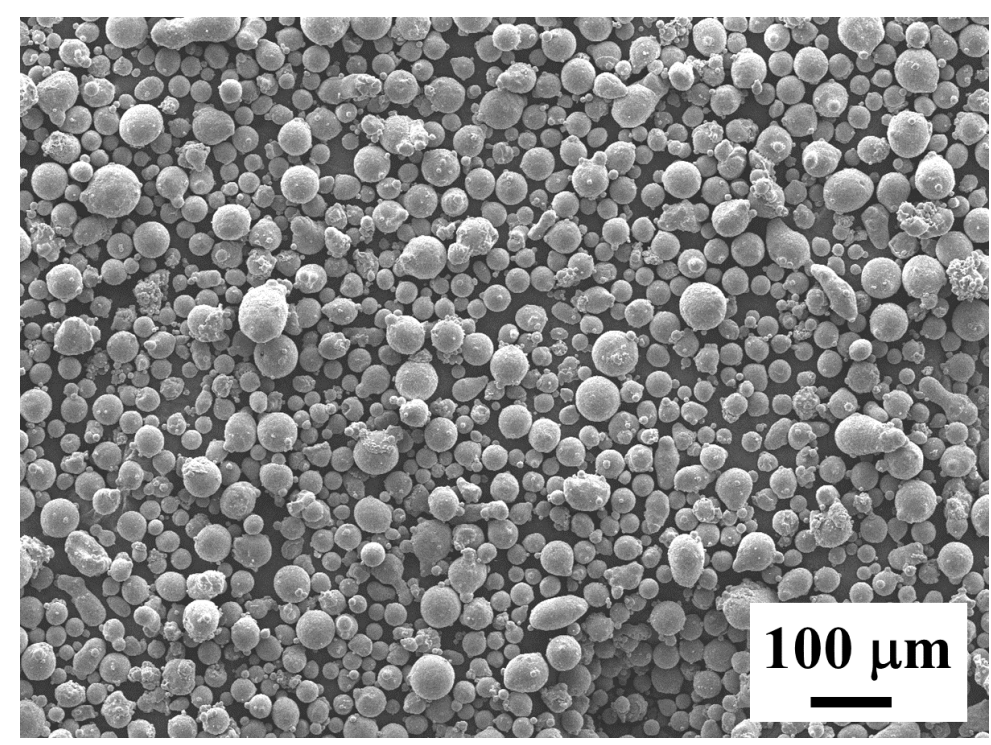

Figure 1. The SEM image of the pre-alloyed Scalmalloy powders.

Table 1. Summary of the 3D printing parameters used in this study.

\begin{tabular}{ccccc}
\hline $\begin{array}{c}\text { Laser Power } \\
(\mathbf{W})\end{array}$ & $\begin{array}{c}\text { Scan Speed } \\
(\mathbf{m m} / \mathbf{s})\end{array}$ & $\begin{array}{c}\text { Hatch Distance } \\
(\mathbf{m m})\end{array}$ & $\begin{array}{c}\text { Layer } \\
\text { Thickness } \\
(\mathbf{m m})\end{array}$ & $\begin{array}{c}\mathbf{E}=\mathbf{P} / \mathbf{v h t} \\
\left(\mathbf{J} / \mathbf{m m}^{\mathbf{3}}\right)\end{array}$ \\
\hline 200 & 500 & 0.05 & 0.03 & 266.7 \\
\hline
\end{tabular}

The geometry of the sample for the OM, EBSD, and TEM examination is a $1 \times 1$ $\times 1 \mathrm{~cm}^{3}$ cubic. After the heat treatment, all the samples were ground (with sandpaper) and polished (with Alumina powders). After the sample polishing, the microstructure of the samples was observed at the Joint Center of High Valued Instruments, National Sun Yat-sen University by using the Leica DFC420 microscope (Leica Microsystems GmbH, Wetzlar, Germany), the electron backscattered diffraction (EBSD) using the Zeiss Supra 55 SEM (Carl Zeiss AG, Jena, Germany)with an EBSD system, and the PHILIPS CM200 (Koninklijke Philips N.V., Amsterdam, The Netherlands) transmission electron microscope (TEM) with an operating voltage of $200 \mathrm{kV}$. After mechanical grinding and polishing, the samples were etched with a solution of $4 \% \mathrm{HNO}_{3}+2 \% \mathrm{HF}+94 \%$ pure water before the OM examination. Before EBSD examination, the samples were electro-polished with an electrolyte of methanol and nitric acid (with the volume fraction of 7:3) using a voltage of $20 \mathrm{~V}$ for $1 \mathrm{~s}$ under a temperature of $25{ }^{\circ} \mathrm{C}$ after mechanical grinding and polishing. Additionally, the EBSD patterns were acquired at an acceleration voltage of $20 \mathrm{kV}$. The size and volume fraction of micron-sized and submicron-sized grains were measured and calculated using ImageJ software version 1.52a (NIH, Bethesda, MD, USA). TEM foil samples were prepared using focus ion beam (FIB) milling. The size and volume fraction of the precipitates were measured and calculated using ImageJ software version 1.52a as well, and the mean precipitate spacing was determined by subtracting the mean precipitate diameter from the mean center-center distance (estimating each group of samples through three TEM images of which the observed area was about $1400 \mathrm{~nm} \times$ $970 \mathrm{~nm}$ and the foil thickness was $100 \mathrm{~nm}$ ). After that, the volume fraction of the precipitates which was measured and calculated using ImageJ software was corrected by the following equation [31,32]:

$$
f_{V}=\frac{N \bar{v}}{V}
$$


where $f_{V}$ is the volume fraction of the precipitates, $V$ is the investigated volume (the observed area and thickness of the foils along the viewing direction), $N$ is the precipitate number (which can be obtained by ImageJ software as well), and $\bar{v}$ is the average sphere volume of precipitations, which can be calculated using:

$$
\bar{v}=\frac{\pi}{6} d^{3}
$$

where $d$ is the diameter of the average precipitation size. Meanwhile, the characteristic of X-ray diffraction (XRD) was measured using the SIEMENS D5000 X-ray diffractometer (Siemens AG, Mülheim, Germany) with radiation wavelength $\lambda=1.5406 \AA$ of $\mathrm{Cu} \mathrm{K} \mathrm{K}_{\alpha}$, under the working voltage of $40 \mathrm{kV}$, current of $30 \mathrm{~mA}$, and the scan angle was from $20^{\circ}$ to $80^{\circ}$.

The 3D-printed Scalmalloy samples for the tensile test were prepared referring to the ASTM E8 standard for subsized specimens. The gauge length is $25 \mathrm{~mm}$, the width is $6 \mathrm{~mm}$, and the thickness is $1.5 \mathrm{~mm}$, but the length of the grip section is shorter, as shown in Figure 2. Before the tensile test, the samples were wire cut and ground. The tensile tests were performed using the Instron 5582 universal testing machine (Instron Corporation, Norwood, MA, USA) at least 3 times at room temperature under a strain rate of $1 \times 10^{-4} \mathrm{~s}^{-1}$. Meanwhile, no extensometer was used to obtain the tensile curves. The tensile test results and curves were corrected by the deduction of the elastic deformation of the testing machine itself which was estimated from the results of tensile test specimens with known properties.

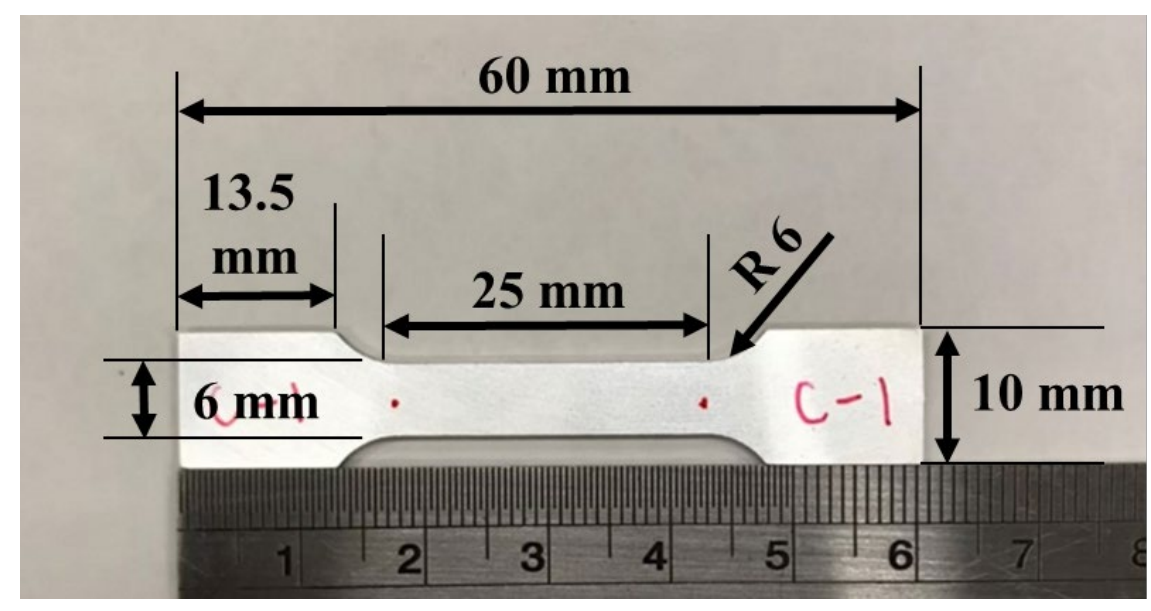

Figure 2. Geometry of dog-bone-like tensile test specimens of the 3D-printed Scalmalloy, the size and geometry of the sample is comparable to the ASTM E8 standard, but the length of grip section is shorter.

\section{Results and Discussion}

\subsection{Microstructure Observations}

After the 3D printing, the density of all samples was measured by the Archimedes method. The relative density of the 3D-printed samples was calculated according to the following formula:

$$
\varepsilon=\left(\rho / \rho_{\mathrm{s}}\right) \times 100
$$

where $\rho$ and $\rho_{\mathrm{s}}$ are the density of the 3D-printed sample and the theoretical density $\left(2.67 \mathrm{~g} / \mathrm{cm}^{3}\right.$ for Scalmalloy), respectively. The measured density is $2.666 \pm 0.006 \mathrm{~g} / \mathrm{cm}^{3}$ for all samples with/without heat-treatment and the calculated densification of the sample was $99.85 \%$.

Since the mechanical properties of the heat-treated Scalmalloy could be affected by the Hall-Petch relation (grain size) and the size/distribution of precipitation, the microstructure feature of heat-treated samples was observed by EBSD, XRD, and TEM, respectively. 
To identify how grain size varies according to the heat treatment parameter, all the samples were examined by EBSD; the EBSD images of the samples are shown in Figure 3. The EBSD images were all taken from the side of the samples to make sure the grain size difference from the surface to the inside of the melt pool can be evaluated. In Figure $3 a, c, e, g$, the presence of submicron-sized grains is observed in darker regions and micron-sized grains were observed in the regions with colors in EBSD results. The size of the submicron-sized grain and micron-sized grain can be measured in the enlarged EBSD images, as shown in Figure $3 b, d, f, h$. Meanwhile, the distribution of submicron-sized grains and micron-sized grains from the surface to the inside of the melt pool was due to the temperature gradient and cooling rate difference. To evaluate the grain size difference with/without heat treatment, the grain size and volume fraction of the micron-sized grains and submicron-sized grains were measured and calculated by ImageJ software version 1.52a, and the results are summarized in Table 2. According to the EBSD observation, the grain size difference with/without heat treatment is less than $10 \%$ since there is no obvious recrystallization due to the following two reasons: first, no cold deformation was performed on 3D-printed samples, and thus recrystallization is expected to be difficult due to the lack of driving force; second, the addition of Sc may limit recrystallization during heat treatment. Even when the heat-treatment is performed at a high temperature (about $520^{\circ} \mathrm{C}$ ), the observed Scalmalloy exhibit strong resistance to recrystallization. Since recrystallization occurs only after these precipitates have lost their coherency, the strong drag effect of these precipitates may be due to the fact that they are coherent with the Al matrix and very stable thermally against loss of coherency and coarsening $[1,33]$. Thus, the mechanical properties might not be significantly affected by such a slight grain size difference, according to the Hall-Petch equation.
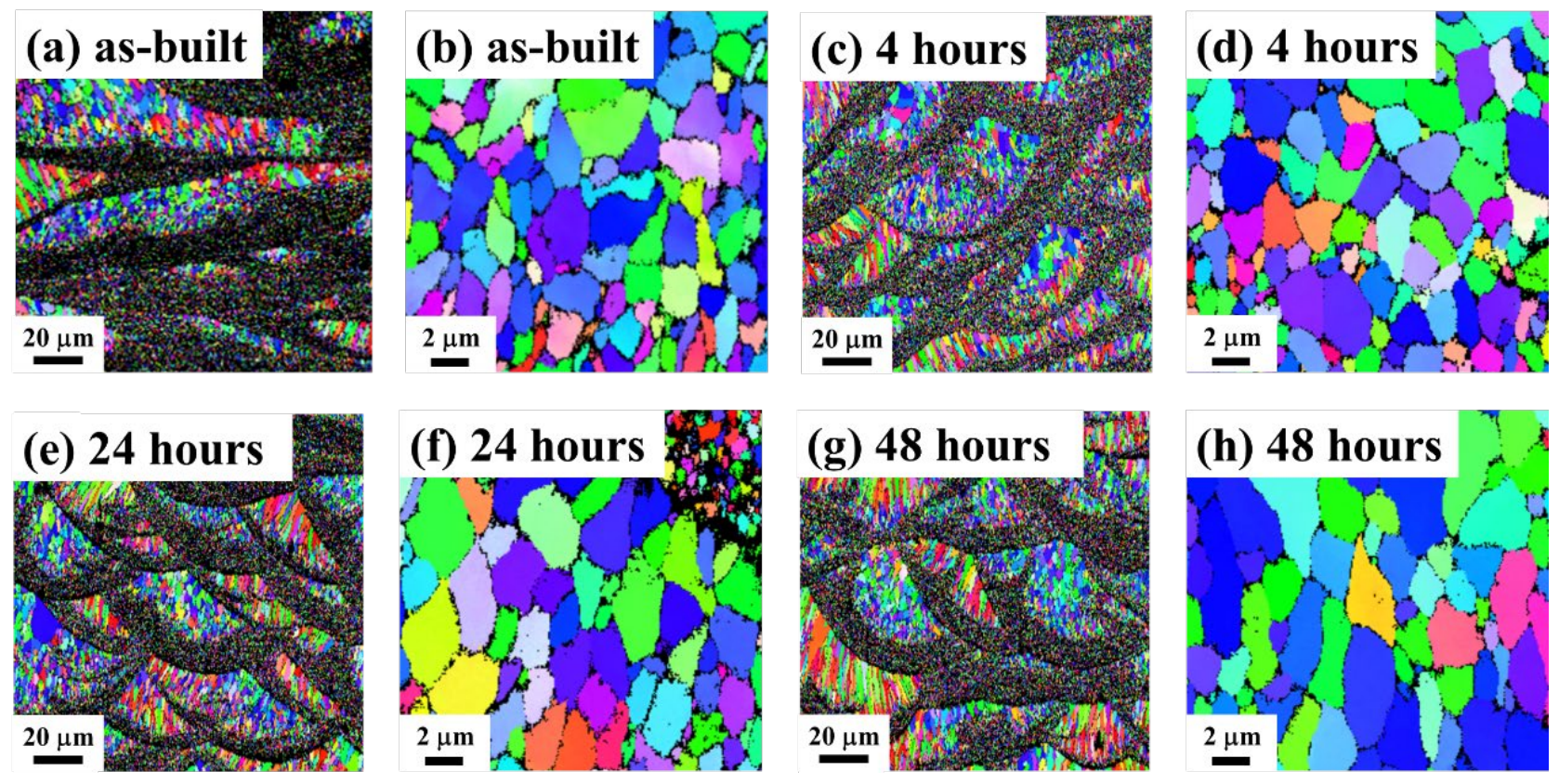

Figure 3. The EBSD images of $(\mathbf{a}, \mathbf{b})$ as-built sample, (c,d) heat-treated sample at $325^{\circ} \mathrm{C}$ for $4 \mathrm{~h},(\mathbf{e}, \mathbf{f})$ sample heat-treated at $325^{\circ} \mathrm{C}$ for $24 \mathrm{~h}$, and $(\mathbf{g}, \mathbf{h})$ heat-treated sample at $325^{\circ} \mathrm{C}$ for $48 \mathrm{~h}$.

On the other hand, the samples were analyzed by XRD and TEM to evaluate the size and volume fraction evolution of $\mathrm{Al}_{3} \mathrm{Sc}$ precipitate with/without heat treatment. The XRD results are shown in Figure 4, which indicates that only $\alpha$ phase has been observed no matter as-built or with short/long time heat treatment. However, the feature of the fine grain of 3D-printed Scalmalloy is caused by the presence of nano-sized $\mathrm{Al}_{3} \mathrm{Sc}$ which can be also observed in the following TEM results, and thus the $\mathrm{Al}_{3} \mathrm{Sc}$ peak may be below the detection limit. Thus, the mechanical properties of all samples in this study would not 
be affected by oxidation or other unexpected micron-sized phases but only by nano-sized precipitation.

Table 2. The grain size and volume fraction of micron-sized grains and submicron-sized grains of the as-built and heattreated Scalmalloy samples.

\begin{tabular}{|c|c|c|c|c|c|}
\hline \multirow{2}{*}{ Sample } & \multicolumn{2}{|c|}{ Micron-Sized Grains } & \multicolumn{2}{|c|}{ Submicron-Sized Grains } & \multirow{2}{*}{$\begin{array}{l}\text { Average Grain Size } \\
\qquad(\mu \mathrm{m})\end{array}$} \\
\hline & $\begin{array}{l}\text { Grain Size } \\
\quad(\mu \mathrm{m})\end{array}$ & $\begin{array}{c}\text { Volume Fraction } \\
(\%)\end{array}$ & $\begin{array}{l}\text { Grain Size } \\
(\mu \mathrm{m})\end{array}$ & $\begin{array}{c}\text { Volume Fraction } \\
(\%)\end{array}$ & \\
\hline As-Built & $2.2 \pm 0.3$ & $51.0 \pm 12.1$ & $0.4 \pm 0.0$ & $49.0 \pm 12.1$ & 1.30 \\
\hline HT-4 & $1.8 \pm 0.1$ & $54.5 \pm 8.1$ & $0.4 \pm 0.0$ & $45.5 \pm 8.1$ & 1.19 \\
\hline HT-24 & $1.8 \pm 0.0$ & $52.0 \pm 7.8$ & $0.4 \pm 0.0$ & $48.0 \pm 7.8$ & 1.15 \\
\hline HT- 48 & $2.1 \pm 0.1$ & $52.5 \pm 6.3$ & $0.4 \pm 0.0$ & $47.5 \pm 6.3$ & 1.28 \\
\hline
\end{tabular}

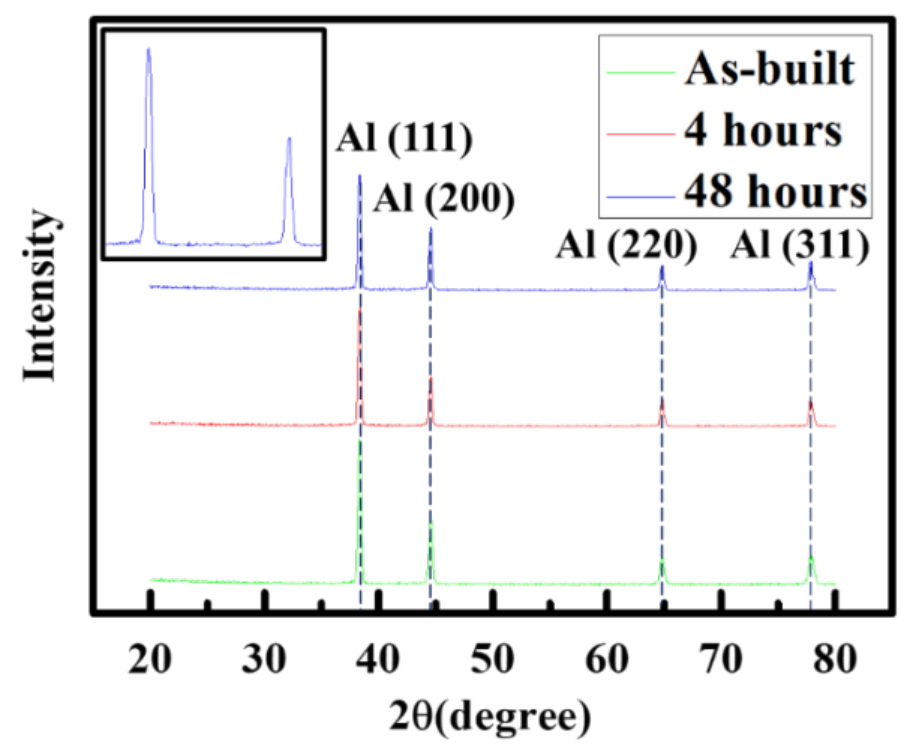

Figure 4. XRD results of the as-built and heat-treated samples.

To evaluate the heat-treatment effects on the microstructure evolution, especially the elimination of the precipitate free zone, all TEM samples (with/without heat-treatment) were prepared using the focus ion beam (FIB) milling in the micron-sized grain region. Although the micron-sized grain region (inside the melt pool) and the submicron-sized grain region (on the surface of the melt pool) can be observed at the same time after etching, the TEM sample can be successfully prepared using FIB in the micron-sized grain region due to the surface roughness being better than that of the submicron-sized grain region, as shown in Figure 5.

In Figure 6, it shows the dark field (DF) TEM electron micrograph with $\mathrm{Al}_{3} \mathrm{Sc}$ selected area diffraction pattern (SADP) results of the 3D-printed Scalmalloy samples with/without heat-treatment; the aperture for dark field imaging is indicated by the red circle in SADP. According to the SADP results, the precipitate was specified as $\mathrm{Al}_{3} \mathrm{Sc}$, which corresponds to that calculated using CaRIne Crystallography version 3.1. Before heat-treatment, the distribution of $\mathrm{Al}_{3} \mathrm{Sc}$ precipitate was non-uniform and the precipitate only embedded in a few grains, and the regions which were found to be free of precipitates (the region size exceeds $300 \mathrm{~nm}$ ) is called precipitate free zone (PFZ), as shown in Figure 6a. Due to the lack of precipitates, there is no precipitate strengthening in the precipitate free zone and thus it is considered the reason for the low yield stress of as-built Scalmalloy. After $4 \mathrm{~h}, 24 \mathrm{~h}$, or $48 \mathrm{~h}$ of heat-treatment, the precipitate free zone was not observed in the samples due to the uniform distribution of precipitates. According to the TEM results, the precipitation size of the as-built sample was $14.9 \mathrm{~nm}$, and increased from $12.0 \mathrm{~nm}$ to $20.0 \mathrm{~nm}$, with heat-treated 
time increasing from $4 \mathrm{~h}$ to $48 \mathrm{~h}$, as shown in Table 3. Meanwhile, in Figure $6 \mathrm{~b}-\mathrm{d}$, after $4 \mathrm{~h}$, $24 \mathrm{~h}$, and $48 \mathrm{~h}$ of heat-treatment, the volume fraction of $\mathrm{Al}_{3} \mathrm{Sc}$ precipitate increased from 0.048 (as-built) to $0.095 \%, 0.118 \%$, and $0.119 \%$, respectively.

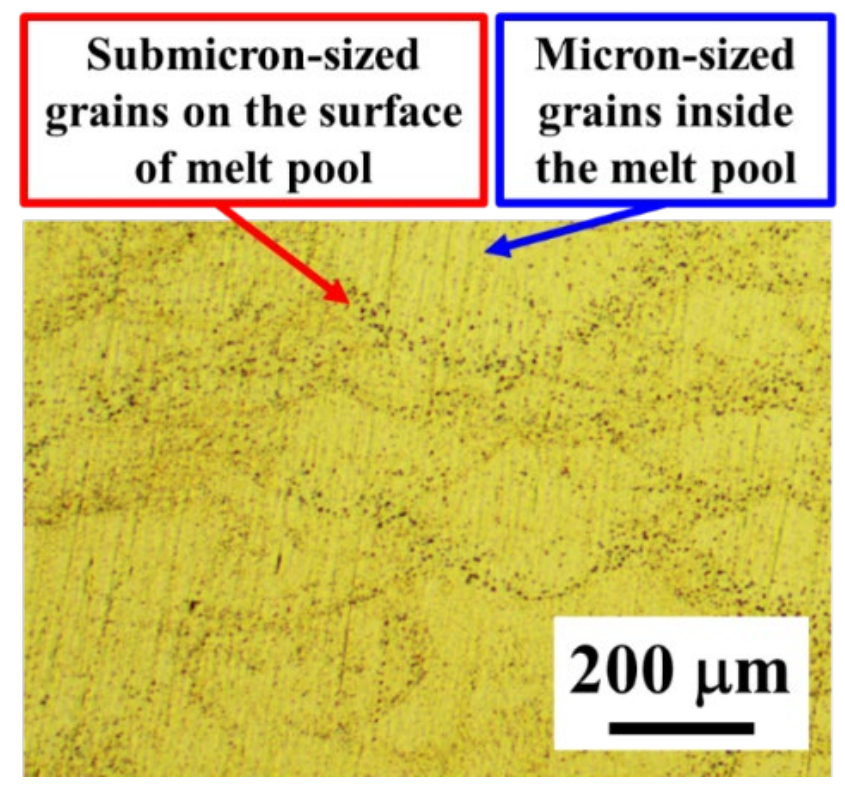

Figure 5. Optical microscope (OM) image of the etched sample, the TEM samples were prepared using the focus ion beam (FIB) milling in the micron-sized grain region (inside the melt pool).
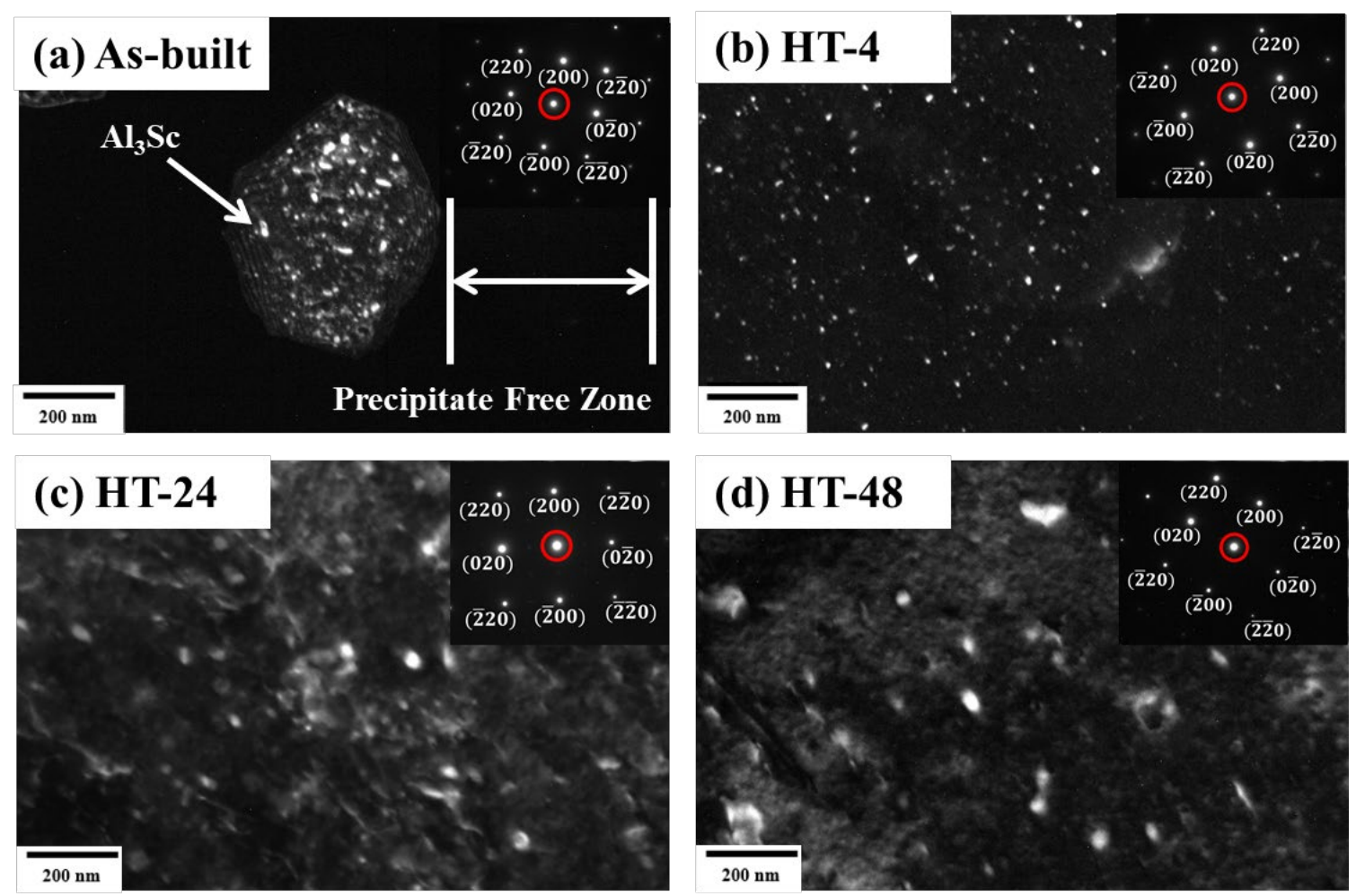

Figure 6. TEM images and the corresponding selected area diffraction pattern (SADP) of (a) the as-built sample, (b) heat-treated sample at $325^{\circ} \mathrm{C}$ for $4 \mathrm{~h}$, (c) sample heat-treated at $325^{\circ} \mathrm{C}$ for $24 \mathrm{~h}$, and (d) heat-treated sample at $325^{\circ} \mathrm{C}$ for $48 \mathrm{~h}$. The aperture for dark field imaging is indicated by the red circle in SADP. 
Table 3. Summary of $\mathrm{Al}_{3} \mathrm{Sc}$ precipitation size and volume fraction of the as-built and heat-treated samples Scalmalloy samples.

\begin{tabular}{ccccc}
\hline Sample & $\begin{array}{c}\mathrm{Al}_{3} \text { Sc Spacing } \\
(\mathbf{n m})\end{array}$ & $\mathbf{A l}_{3}$ Sc Size (nm) & $\begin{array}{c}\mathbf{A l}_{3} \text { Sc Volume } \\
\text { Fraction (\%) }\end{array}$ & $\begin{array}{c}\text { Volume Fraction } \\
\mathbf{A l}_{3} \text { Sc Size }\end{array}$ \\
\hline As-Built & & $14.9 \pm 0.8$ & $0.048 \pm 0.003$ & 0.00322 \\
HT-4 & $21.0 \pm 2.5$ & $12.0 \pm 0.1$ & $0.095 \pm 0.003$ & 0.00792 \\
HT-24 & $37.4 \pm 3.3$ & $18.3 \pm 1.0$ & $0.118 \pm 0.008$ & 0.00645 \\
HT-48 & $45.6 \pm 0.7$ & $20.0 \pm 0.3$ & $0.119 \pm 0.006$ & 0.00595 \\
\hline
\end{tabular}

The presence of a precipitate free zone is due to the non-uniform distribution of $\mathrm{Al}_{3} \mathrm{Sc}$ precipitate according to a high cooling rate and different thermal history during the $3 \mathrm{D}$ printing process. The small size and small amount of $\mathrm{Al}_{3} \mathrm{Sc}$ was first precipitated during the rapid cooling and solidification of the molten powders. Following, the re-melting occurred due to the overlap between the nearby molten pool and thus the growth of $\mathrm{Al}_{3} \mathrm{Sc}$ occurred, as shown in Figure 7. However, only part of $\mathrm{Al}_{3} \mathrm{Sc}$ was precipitated during the $3 \mathrm{D}$ printing process due to the high cooling rate. Thus, it may be the reason that only a few precipitates (which precipitated and grew in the re-melting region) were observed, but the average size is larger than that of the sample with $4 \mathrm{~h}$ of heat-treatment. After proper heat-treatment, the $\mathrm{Al}_{3} \mathrm{Sc}$ precipitated uniformly and grew with increasing heat-treatment time. Hence, the average precipitate size of the 4 -h heat-treated sample is smaller than that of the as-built sample due to the small size of $\mathrm{Al}_{3} \mathrm{Sc}$ as precipitated from the matrix (higher volume fraction but smaller precipitate size). After that, the precipitate size and volume fraction increased with increasing heat-treatment time, as shown in Table 3.

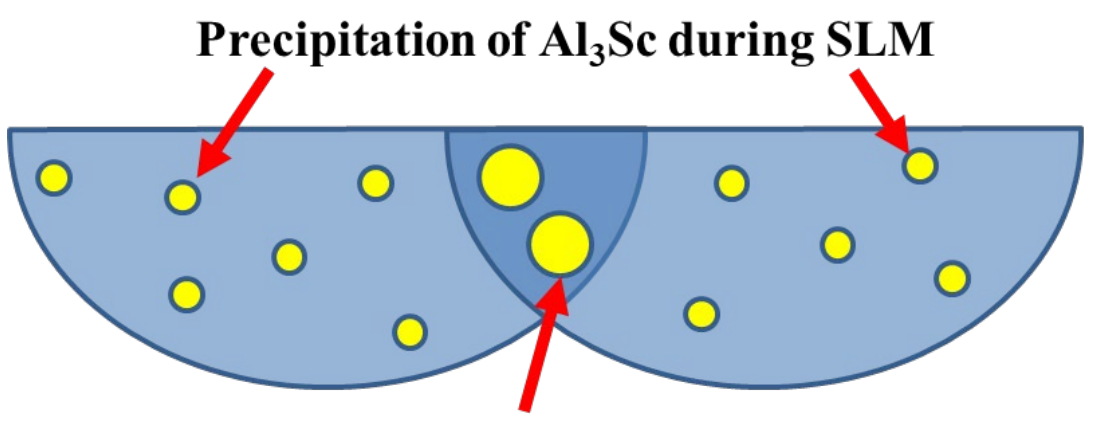

\section{Growth of $\mathrm{Al}_{3} \mathrm{Sc}$ in re-melting region}

Figure 7. Schematic illustration of the precipitate size difference due to different thermal histories in the melt pool.

\subsection{Mechanical Properties}

The stress-strain curves of the as-built sample and the samples with three different heat treatment parameters are shown in Figure 8. The mechanical property results are summarized in Table 4. Compared with the as-built sample, the yield stress of the samples after heat treatment increased significantly. Meanwhile, the elongation of all heat-treated samples was about $10 \%$, which can meet the requirements of most applications. According to current results, the yield stress of the sample after heat treatment at $325^{\circ} \mathrm{C}$ for $4 \mathrm{~h}$ is higher than the other samples. Similar to the results of microhardness, the mechanical properties, especially the yield stress of the heat-treated samples, were decreased with increasing heat-treatment time. 

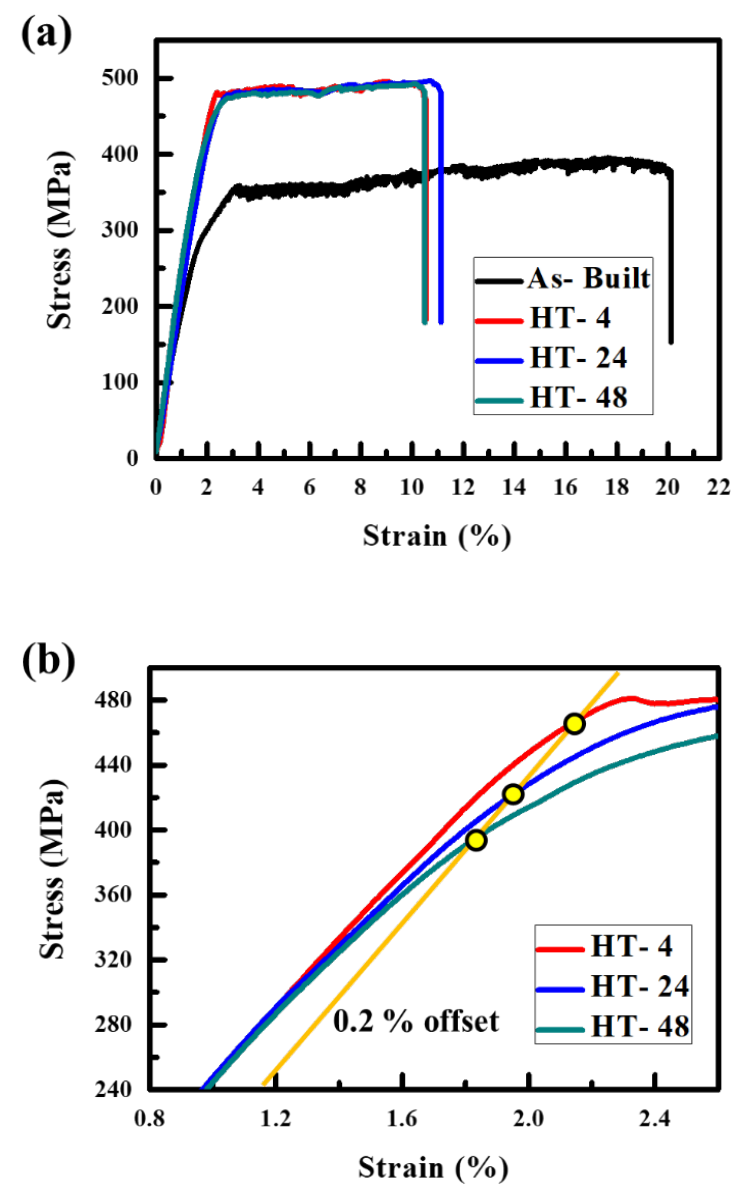

Figure 8. (a) Tensile stress-strain curves of the as-built and heat-treated 3D-printed Scalmalloy samples, and (b) the enlarged image shows the difference in yield stress of heat-treated samples.

Table 4. Summary of tension mechanical properties of the 3D-printed Scalmalloy samples with different processing parameters.

\begin{tabular}{ccc}
\hline Sample & Yield Stress (0.2\% Offset) $\mathbf{( M P a )}$ & Elongation (\%) \\
\hline As-Built & $286.9 \pm 6.2$ & $18.4 \pm 2.8$ \\
HT-4 & $455.8 \pm 8.9$ & $10.3 \pm 0.2$ \\
HT-24 & $415.2 \pm 22.4$ & $11.0 \pm 0.1$ \\
HT-48 & $365.9 \pm 22.8$ & $10.0 \pm 0.5$ \\
\hline
\end{tabular}

Since there was no obvious phase transformation or grain size increase, the mechanical properties seem to be affected by the precipitate size, volume fraction, and distribution. According to the TEM results, a small amount and non-uniform distribution of precipitate had been observed in the as-built sample and thus there was a precipitate free zone which may cause the mechanical property to decrease. After heat-treatment, the precipitate size decreases and volume fraction increases which results in a yield stress improvement from 286.9 $\mathrm{MPa}$ to $455.8 \mathrm{MPa}$, due to the elimination of a precipitate free zone. After that, the yield stress is decreased with increasing heat-treatment time. It is worth noting that even though the grain size of the as-built sample is smaller than that of the samples with $24 \mathrm{~h}$ or $48 \mathrm{~h}$ heat-treatment, the yield stress of the as-built sample was lower than that of heat-treated samples. Moreover, the yield stress variation also did not follow the variation of $\mathrm{Al}_{3} \mathrm{Sc}$ volume fraction.

The elimination of the precipitate free zone (which means the uniform distribution of precipitates) plays an important role in improving the mechanical properties. According to the precipitation strengthening model, the yield stress increases with decreasing precipitate 
spacing (Orowan's law). However, due to the presence of the precipitate free zone, it was hard to measure the precipitate spacing of the as-built sample and could have resulted in a miscalculation. Thus, to evaluate the precipitation strengthening effects on mechanical properties, we proposed the ratio of volume fraction to size which is inversely proportional to the precipitate spacing. Additionally, the uniformity of precipitate distribution is increased with decreasing precipitate size and increasing volume fraction, which can be also described as the ratio of volume fraction to size, as shown in Table 3. The relation between the yield stress and the ratio of volume fraction to size is shown in Figure 9. The precipitate distribution uniformity of the 4-h heat-treated sample was higher than the others due to the smallest precipitate size and therefore had the highest yield stress. On the other hand, the sample with $48 \mathrm{~h}$ heat-treatment showed the highest precipitate volume fraction but the largest precipitate size and therefore distribution uniformity and thus the yield stress was worse than the other heat-treated samples.

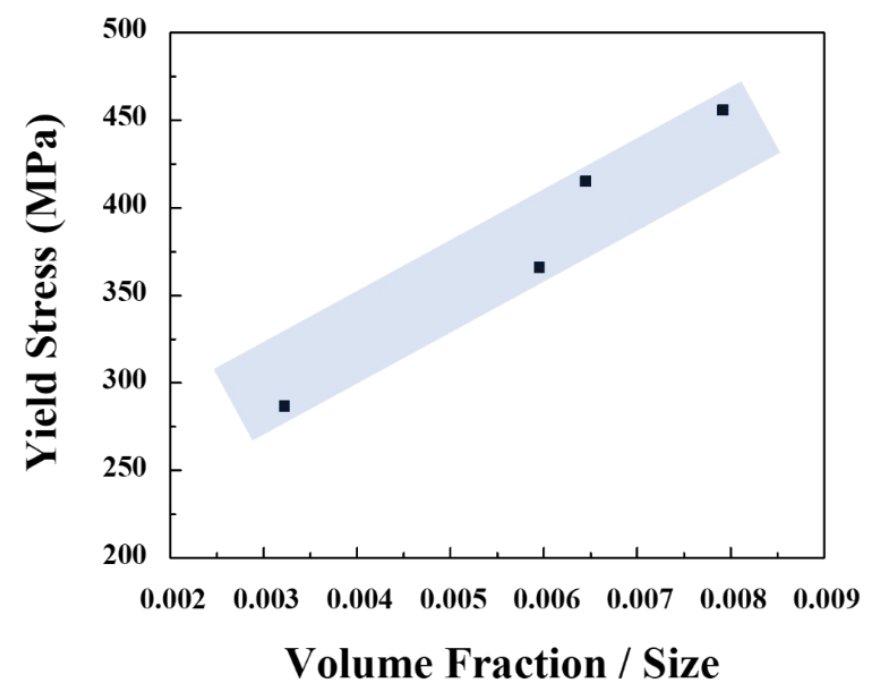

Figure 9. Schematic illustration of the relation between the yield stress and ratio of precipitation volume fraction to precipitation size.

\section{Conclusions}

The relationship between heat-treatment parameter, microstructure, and mechanical properties of 3D-printed Scalmalloy was explored in this study. According to the results and discussion, the following conclusions are drawn.

1. After heat-treatment, there is no obvious grain size change or phase transformation. On the other hand, the size and distribution of precipitates are greatly affected by the heat-treatment parameter. Before heat-treatment, the distribution of precipitates was non-uniform, and thus there were regions which, found to be free of precipitates, are called the precipitate free zones (PFZ). After proper heat-treatment, the $\mathrm{Al}_{3} \mathrm{Sc}$ precipitated uniformly and grew (from $12.0 \mathrm{~nm}$ to $20.0 \mathrm{~nm}$ ) with increasing heattreatment time.

2. Since the region free of precipitates was no longer observed in the samples after $4 \mathrm{~h}$ of heat-treatment, the precipitate free zone seemed to be eliminated. The mechanical properties of 3D-printed Scalmalloy samples, especially the yield stress, greatly improved from 286.9 MPa to $455.8 \mathrm{MPa}$. After that, the yield stress is decreased with increasing heat-treatment time.

3. According to the precipitation strengthening model, the yield stress increases with decreasing precipitate spacing (Orowan's law). However, due to the presence of the precipitate free zone, it was hard to measure the precipitate spacing of the as-built sample and this could result in a miscalculation. Thus, in this study, we found that the precipitation strengthening effects on mechanical properties can be described as the ratio of volume fraction to size when the precipitate spacing is hard to measured. 
Author Contributions: Conceptualization, C.N.K.; methodology, C.N.K.; formal analysis, P.C.P., D.H.L., and C.Y.C.; investigation, P.C.P., D.H.L., and C.Y.C.; resources, C.N.K.; data curation, C.N.K., P.C.P., D.H.L., and C.Y.C.; writing-original draft preparation, C.N.K.; supervision, C.N.K.; project administration, C.N.K.; funding acquisition, C.N.K. All authors have read and agreed to the published version of the manuscript.

Funding: This research was funded by the Ministry of Science and Technology of Taiwan, ROC, under project No. MOST 109-2218-E-468-001, MOST 109-2622-E-468-003, and Ministry of National Defense, ROC, under project No. MND XV09227P783-CS.

Institutional Review Board Statement: Not applicable.

Informed Consent Statement: Not applicable.

Data Availability Statement: Not applicable.

Acknowledgments: The authors are grateful for the experimental support of Liu-Wen Chang and Ker-Chang Hsieh in the Department of Materials and Optoelectronic Science, National Sun Yat-sen University. Meanwhile, the authors are also grateful for Kuang-Kuo Wang at National Sun Yat-sen University for assistance with TEM (EM001400) experiments and the support from Heraeus Group and Circle Metal Powder Co., Ltd.

Conflicts of Interest: The authors declare no conflict of interest.

\section{References}

1. Spierings, A.B.; Dawson, K.; Kern, K.; Palm, F.; Wegener, K. SLM-processed Sc- and Zr- modified Al-Mg alloy: Mechanical properties and microstructural effects of heat treatment. Mater. Sci. Eng. A 2017, 701, 264-273. [CrossRef]

2. Zhou, J.; Shrotriya, P.; Soboyejo, W.O. On the deformation of aluminum lattice block structures: From struts to structures. Mech. Mater. 2004, 36, 723-737. [CrossRef]

3. Yeong, W.-Y.; Chua, C.-K.; Leong, K.-F.; Chandrasekaran, M. Rapid prototyping in tissue engineering: Challenges and potential. Trends Biotechnol. 2004, 22, 643-652. [CrossRef]

4. Wang, X.; Xu, S.; Zhou, S.; Xu, W.; Leary, M.; Choong, P.; Qian, M.; Brandt, M.; Xie, Y.M. Topological design and additive manufacturing of porous metals for bone scaffolds and orthopaedic implants: A review. Biomaterials 2016, 83, 127-141. [CrossRef]

5. Khairallah, S.A.; Anderson, A.T.; Rubenchik, A.; King, W.E. Laser powder-bed fusion additive manufacturing: Physics of complex melt flow and formation mechanisms of pores, spatter, and denudation zones. Acta Mater. 2016, 108, 36-45. [CrossRef]

6. Herzog, D.; Seyda, V.; Wycisk, E.; Emmelmann, C. Additive manufacturing of metals. Acta Mater. 2016, 117, 371-392. [CrossRef]

7. Shuai, C.; Yang, Y.; Feng, P.; Peng, S.; Guo, W.; Min, A.; Gao, C. A multi-scale porous scaffold fabricated by a combined additive manufacturing and chemical etching process. Int. J. Bioprint. 2018, 4, 133. [CrossRef] [PubMed]

8. Yang, Y.; Wang, G.; Liang, H.; Gao, C.; Peng, S.; Shen, L.; Shuai, C. Additive manufacturing of bone scaffolds. Int. J. Bioprint. 2019, 5, 148. [CrossRef] [PubMed]

9. Kolan, K.; Li, J.; Roberts, S.; Semon, J.A.; Park, J.; Day, D.E.; Leu, M.C. Near-field electrospinning of a polymer/bioactive glass composite to fabricate 3D biomimetic structures. Int. J. Bioprint. 2019, 5, 163. [CrossRef] [PubMed]

10. Shie, M.-Y.; Fang, H.-Y.; Lin, Y.-H.; Lee, A.K.-X.; Yu, J.; Chen, Y.-W. Application of piezoelectric cells printing on three-dimensional porous bioceramic scaffold for bone regeneration. Int. J. Bioprint. 2019, 5, 210. [CrossRef] [PubMed]

11. Chua, C.K.; Leong, K.F. 3D Printing and Additive Manufacturing: Principles and Applications, 5th ed.; World Scientific: Singapore, 2017.

12. Chua, C.K.; Leong, K.F.; Lim, C.S. Rapid Prototyping: Principles and Applications; World Scientific: Singapore, 2010.

13. Gibson, I.; Rosen, D.W.; Stucker, B. Additive Manufacturing Technologies; Springer: Berlin/Heidelberg, Germany, 2010.

14. Liu, Y.J.; Li, S.J.; Wang, H.L.; Hou, W.T.; Hao, Y.L.; Yang, R.; Sercombe, T.B.; Zhang, L.C. Microstructure, defects and mechanical behavior of beta-type titanium porous structures manufactured by electron beam melting and selective laser melting. Acta Mater. 2016, 113, 56-67. [CrossRef]

15. Zhao, X.L.; Li, S.J.; Zhang, M.; Liu, Y.D.; Sercombe, T.B.; Wang, S.G.; Hao, Y.L.; Yang, R.; Murr, L.E. Comparison of the microstructures and mechanical properties of Ti-6Al-4V fabricated by selective laser melting and electron beam melting. Mater. Des. 2016, 95, 21-31. [CrossRef]

16. Sudarmadji, N.; Tan, J.Y.; Leong, K.F.; Chua, C.K.; Loh, Y.T. Investigation of the mechanical properties and porosity relationships in selective laser-sintered polyhedral for functionally graded scaffolds. Acta Biomater. 2011, 7, 530-537. [CrossRef] [PubMed]

17. Murr, L.E. Open-cellular metal implant design and fabrication for biomechanical compatibility with bone using electron beam melting. J. Mech. Behav. Biomed. Mater. 2017, 76, 164-177. [CrossRef] [PubMed]

18. Chen, S.Y.; Kuo, C.N.; Su, Y.L.; Huang, J.C.; Wu, Y.C.; Lin, Y.H.; Chung, Y.C.; Ng, C.H. Microstructure and fracture properties of open-cell porous Ti-6Al-4V with high porosity fabricated by electron beam melting. Mater. Charact. 2018, 138, 255-262. [CrossRef]

19. Kuo, C.N.; Chua, C.K.; Peng, P.C.; Chen, Y.W.; Sing, S.L.; Huang, S.; Su, Y.L. Microstructure evolution and mechanical property response via 3D printing parameter development of Al-Sc alloy. Virtual Phys. Prototyp. 2020, 15, 120-129. [CrossRef] 
20. Schmidtke, K.; Palm, F.; Hawkins, A.; Emmelmann, C. Process and Mechanical Properties: Applicability of a Scandium modified Al-alloy for Laser Additive Manufacturing. Phys. Procedia 2011, 12, 369-374. [CrossRef]

21. Jägle, E.A.; Lu, L.; Wu, L.; Raabe, D. Alloy Design for Additive Manufacturing; Max-Planck-Institut: Nijmegen, Germany, 2016; pp. $1-43$.

22. Wang, M.; Li, R.; Yuan, T.; Chen, C.; Zhou, L.; Chen, H.; Zhang, M.; Xie, S. Microstructures and mechanical property of AlMgScZrMn-A comparison between selective laser melting, spark plasma sintering and cast. Mater. Sci. Eng. A 2019, 756, 354-364. [CrossRef]

23. Spierings, A.B.; Dawson, K.; Voegtlin, M.; Palm, F.; Uggowitzer, P.J. Microstructure and mechanical properties of as-processed scandium-modified aluminium using selective laser melting. Cirp Ann. 2016, 65, 213-216. [CrossRef]

24. Spierings, A.B.; Dawson, K.; Heeling, T.; Uggowitzer, P.J.; Schäublin, R.; Palm, F.; Wegener, K. Microstructural features of Sc- and Zr-modified Al-Mg alloys processed by selective laser melting. Mater. Des. 2017, 115, 52-63. [CrossRef]

25. Li, R.; Wang, M.; Yuan, T.; Song, B.; Chen, C.; Zhou, K.; Cao, P. Selective laser melting of a novel Sc and Zr modified Al-6.2 Mg alloy: Processing, microstructure, and properties. Powder Technol. 2017, 319, 117-128. [CrossRef]

26. Spierings, A.B.; Dawson, K.; Uggowitzer, P.J.; Wegener, K. Influence of SLM scan-speed on microstructure, precipitation of Al3Sc particles and mechanical properties in Sc- and Zr-modified Al-Mg alloys. Mater. Des. 2018, 140, 134-143. [CrossRef]

27. Best, J.P.; Maeder, X.; Michler, J.; Spierings, A.B. Mechanical Anisotropy Investigated in theComplex SLM-Processed Sc- and Zr-Modified Al-Mg Alloy Microstructure. Adv. Eng. Mater. 2019, 21, 1801113. [CrossRef]

28. Koutny, D.; Skulina, D.; Pantělejev, L.; Paloušek, D.; Lenczowski, B.; Palm, F.; Nick, A. Processing of Al-Sc aluminum alloy using SLM technology. Procedia Cirp 2018, 74, 44-48. [CrossRef]

29. Churyumov, A.Y.; Pozdniakov, A.V.; Prosviryakov, A.S.; Loginova, I.S.; Daubarayte, D.K.; Ryabov, D.K.; Korolev, V.A.; Solonin, A.N.; Pavlov, M.D.; Valchuk, S.V. Microstructure and mechanical properties of a novel selective laser melted Al-Mg alloy with low Sc content. Mater. Res. Express 2019, 6, 126595. [CrossRef]

30. Mikhaylovskaya, A.V.; Mochugovskiy, A.G.; Levchenko, V.S.; Tabachkova, N.Y.; Mufalo, W.; Portnoy, V.K. Precipitation behavior of L12 Al3Zr phase in Al-Mg-Zr alloy. Mater. Charact. 2018, 139, 30-37. [CrossRef]

31. Andersen, S.J.; Marioara, B.H.C.D. Quantification of small, convex particles by TEM. Ultramicroscopy 2008, 108, 750-762. [CrossRef]

32. Wosik, J.; Dubiel, B.; Kruk, A.; Penkalla, H.-J.; Schubert, F.; Czyrska-Filemonowicz, A. Stereological estimation of microstructural parameters of nickel-based superalloy Waspaloy using TEM methods. Mater. Charact. 2001, 46, 119-123. [CrossRef]

33. Ocenasek, V.; Slamova, M. Resistance to recrystallization due to Sc and Zr addition to Al-Mg alloys. Mater. Charact. 2001, 47, 157-162. [CrossRef] 